\title{
Identity, otherness and the
} virtual double ${ }^{1}$

\section{ABSTRACT}

1.
Interactive media arts offer us new approaches to the role of theatrical representation. Nowadays, digital technology allowe us to explore self-representation in systems that cross over between installation art, theatre and performance. By confronting the subject with his or her orw image these devices question the mechanisms of identification and denegation. Both the theatrical creations and the interactive forms that are examined here invite the speetator to explore the relationship between identification and denegation. All the artistic productions that are studied in this article call for a virtual double that the immersant meets: Liquid Views (1992) and Rigid Waves ([1993] 2008) by Monika Fleischmann and Wolfgang Strauss, Telematic Dreaming ([1992] 2007) by Paul Sermon and Eux (2008) by the Crew company and Sensorama (2009) by the Andwhatbeside(s)death company. In all of these artworks, the participant is encouraged to give less importance to his or her cognitive senses in order to allow his or her sensations to create a representation of himself or herself. The overlap between identity and otherness is therefore to be found at the very heart of the sensitive body.

Theatre constitutes a representative art par excellence. Ever since it first emerged as an art form, and indeed in the many different guises that it has taken over the centuries, theatrical representation has played a key role in the process of bringing together the ideas of presence and absence. The power of theatre originates from the unique confrontation that is brought about

\section{KEYWORDS}

identity otherness virtuality doppelgänger disembodiment sensitive body neurosciences self-consciousness

1. Natasha Slater has translated the article from French. 
2. Term proposed by the artist Char Davies (in Dixon 2007: 372) by the fact that an actor's presence necessarily entails the absence of the character he or she is playing. This clash is at the root of a certain virtuality. As Matthew Causey (2009: 15) reminds us, due to its illusory immediacy, theatre has always been virtual.

Interactive media arts offer us new approaches to the role of theatrical representation. Albeit in a contrasting manner, these two art forms share a common understanding of the function of representation. In the following quote, Simon Penny highlights the different methods of representation apparent in painting, cinema and in media arts:

A painting is an instance of representation. A film is a sequence of representations. Interactive artworks are not instances of representation, they are virtual machines which themselves produce instances of representation based on real-time inputs.

$$
\text { (in Fleischmann and Strauss 2008: 275) }
$$

Both theatre and the interactive arts are based on signs created in our spacetime continuum, to the extent that media artists such as Monika Fleischmann and Wolfgang Strauss view theatre as a more influential paradigm than cinema, which is often referred to as the origin of the media arts.

Both the theatrical creations and the interactive forms that are examined here invite the spectator to explore the elationship between identification and denegation. The theatregoer is plunged into the narrative because of the identification process. The latter is somewhat counterbalanced by denegation (I know that dramatic action is a scenic illusion but I believe in it all the same). A complete immersion in the narrative is impossible due to the fact that the theatrical sign is rooted in reality. The identification-denegation structure is situated at the very heart of the subject's sensitive body within the field of immersive interactive arts. This is plunged into a system that blurs the line between mediated signs trecorded and retransmitted in front of the participant's eyes) and immediate signs. Faced with these contradictory perceptions, we see that it is above all thanks to his or her flesh that the spectator is able to consistently connect thése two stimuli.

Up to his point we have mentioned the representation of the other and the identification of therness. Nowadays, digital technology allows us to explore self-representation in systems that cross over between installation art, theatre and pefformance. By confronting the subject with his or her own image, these devices question the mechanisms of identification and denegation. All the artistic systems that are studied in this article call for a virtual double that the immersant ${ }^{2}$ meets: Liquid Views (1992) and Rigid Waves ([1993] 2008) by Monika Fleischmann and Wolfgang Strauss, Telematic Dreaming ([1992] 2007) by Paul Sermon, Eux (2008) by the Crew company and Sensorama (2009) by the Andwhatbeside(s)death company. The now indistinct boundary between identity and otherness necessitates the use of the whole body in order to perceive the difference. Contrary to the persistent school of thought in cyber culture, virtual experience is above all a bodily experience. It is at the centre of the body of the immersant, in a virtual self-representation, that identity and otherness intertwine.

Performances based on the meeting of a virtual double provide us with an opportunity to study the connections between self and other, body and spirit and flesh and technology. It is possible to identify at least two of the approaches of the virtual double. The first is based on a felt fascination for
1.

2.

3.

4.

5.

6.

7.

8.

9.

10.

11.

12.

13.

14.

15.

16.

17.

18.

19.

20.

21.

22.

23.

24.

25.

26.

27.

28.

29.

30.

31.

32.

33.

34.

35.

36.

37.

38.

39.

40.

41.

42.

43.

44.

45.

46.

47.

48.

49.

50.

51.

52. 
1. one's digital image while the second explores the uncertainty provoked by the

nature of this so-called self-representation.

\section{SELF-IMAGE AND TECHNOLOGICAL FASCINATION: LIQUID VIEWS AND TELEMATIC DREAMING}

The denigration of the physical body by certain branches of virtual culture has already been shown. Deborah Lupton (1995: 100) reminds us that the body is frequently viewed as an obstacle to technological pleasures. On the contrary, a cyborg perfectly embodies a figure released from the constraints of basic bodily functions - this ideal body never needs to go to the toilet and never feels tired. Kevin Robins (1995: 138) develops the widely accepted opinion that states that the rejection of this parasitic body leads to a feeling of transcendence and to the end of the physical body's ability to define identity. Freed from all that is material, the self is transformed into a floating, polymorphous authority. Liquid Views and Telematic Dreaming provide us with examples of this technological fascination. These two important creations were initially presented at the beginning of the 1990s, a decade marked by developments in the domain of Internet and telecommunication. In this context, optimismandenthusiasm for information technology was readily accepted.

Liquid Views reworks the myth of Narcissus into an interactive media installation. Visitors are invited to observe their own reftection on a horizontal, mirror-like screen that produces a watery reflection. As soon as the screen is touched, the image blurs in the same way as a reflection on water.

However, information technology has replaced the phenomenon of natural reflection: the subject is not confronted by a reflect dimage but rather by a video copy that is projected in front of him or her. For steve Dixon (2007: 245), the original myth of the search for the sublime here takes the form of a technological sublime. Nowadays, we are fascinated by technological capacities; human vanity is being dislodged in favour of technological potential, hence an individual's growing ability to identify himself or herslef with a virtual image.

In the same way, the amous performance Telematic Dreaming engenders the process of self-identification with a digital image. This installation is made up of two separate spages, both of which include a bed. One is occupied by

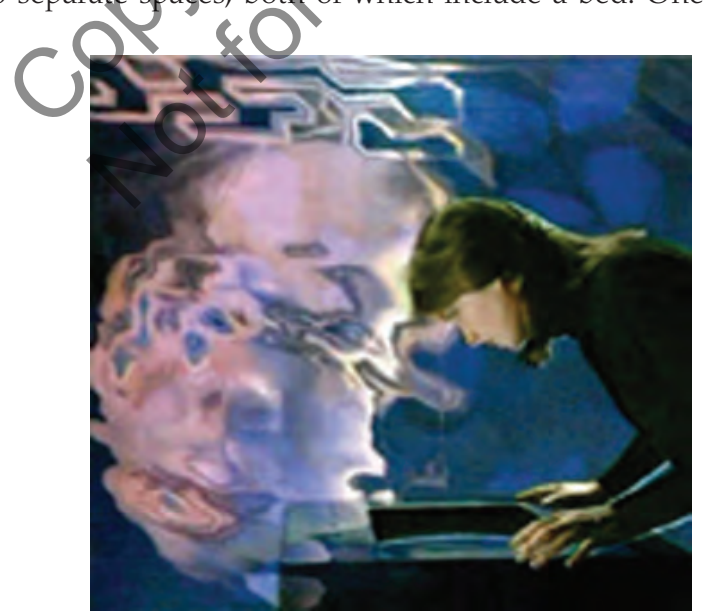

Figure 1: Liquid Views by Monika Fleischmann and Wolfgang Strauss ( Monika Fleischmann and Wolfgang Strauss. 


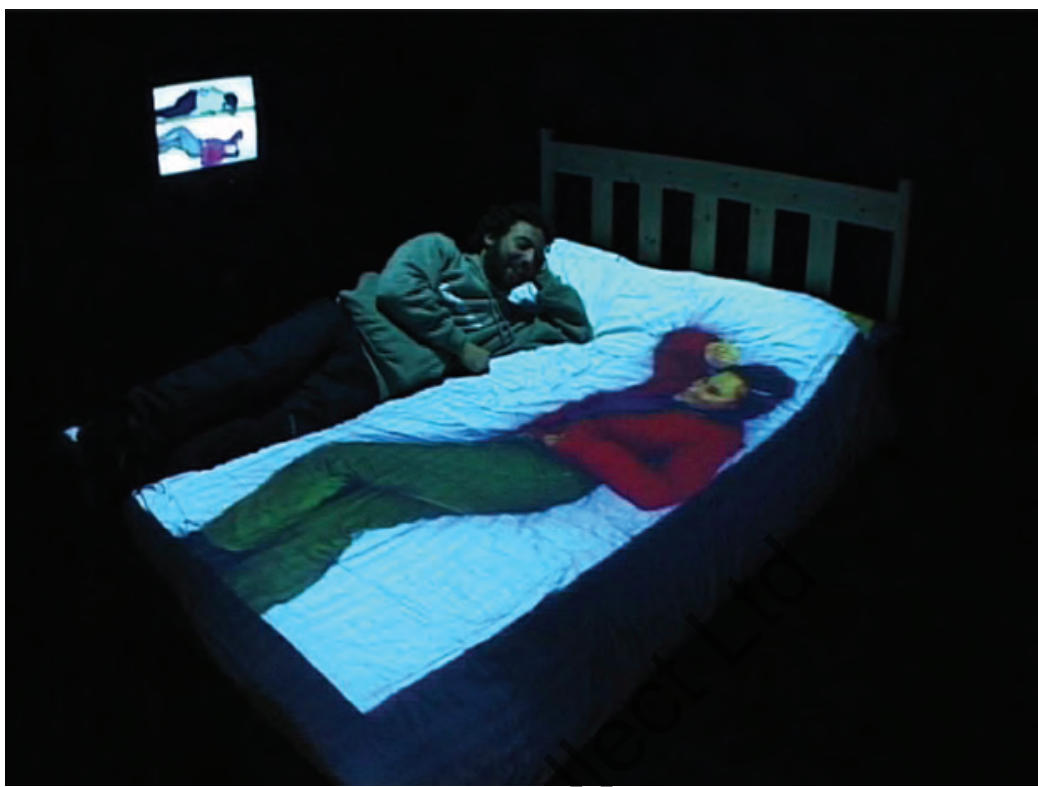

Figure 2: Telematic Dreaming by Paulsermon (C) Paul Sermon [simulation 0029].

the performance artist Susan Kozel and the other by a visitor to the gallery.
Above each of the beds, there is a camera that takes an image of the sleeping Above each of the beds, there is a camera that takes an image of the sleeping
person and projects the image of Susan Kozel onto the bed where the visitor is sleeping and vice versa. In this way, each participant enters into contact with the other's doubl

A monitor rebroadcasts the video image, which combines the two recordings. Therefore the participant sees both the double of a stranger on his or her bed and his or her own-image on the monitor. The physical and digital presence of bodies on the bed generates a telematic space, in which the participants enter into long-distance relationship. Sermon's partner, Andrea Zapo (in Birringer 1999: 376), highlights the fact that the projection of his or her own image allows the individual to exist outside his or her own personal space. His or her very understanding of his or her identity is thus modified:

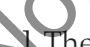

1.. The telematic performance affects consciousness of body and self in such a way that the user's attention, initially focused on the real bed, after a while is no more concentrated on the immediate environment but on the distant telematic one and the virtual movement.

(in Birringer 1999: 375)

This fascinated identification with a digital image relegates the importance of the individual's physical body to second place. However, the fusion between the physical and the virtual body is not absolute. Susan Kozel reports that, upon repetition, this performance transforms the fusion into a bipolar relationship: as soon as the body starts to cramp, it remembers its existence and confronts '[...] the abjection of flesh and the sanitization of technology' (in Dixon 2007: 217). In his analysis of virtual reality, Michael Heim (1995: 73) also evokes the phenomenon of 'coming and going' that occurs between the physical and digital body.
1.

2.

3.

4.

5.

6.

7.

8.

9.

10.

11.

12.

13.

14.

15.

16.

17.

18.

19.

20.

21.

22.

23.

24.

25.

26.

27.

28.

29.

30.

31.

32.

33.

34.

35.

36.

37.

38.

39.

40.

41.

42.

43.

44.

45.

46.

47.

48.

49.

50.

51.

52. 
Despite the fascination for the digital image, the physical body remains. Steve Dixon goes even further and states that the fundamental aim of digital performance is the eradication of any separation between the body and the spirit. This opinion needs to be qualified. Without necessarily considering the physical body as an obstacle to disembodiment, these performances certainly favour identification with the digital body. We agree with Dixon (2007: 215), who says that the iconic body should not make us forget the active or the effective body. However, not forgetting does not mean that one really takes account of or integrates it into one's artistic system.

\section{SELF-IMAGE AND UNCERTAINTY: RIGID WAVES, EUX, SENSORAMA}

Encouraged by the optimism for new methods of telecommunication in the 1990s, Liquid Views and Telematic Dreaming generated an identification of the individual with his or her virtual double. In the second section of this article, the artistic productions referenced will no longer be rooted in technological fascination. Rather, they will neglect the hypnotic dimension of digital techniques in favour of inviting the participant to question his or her own way of perceiving and constructing his or her identity. This questroning is realized through the body. The latter no longer appears as merety an effective body but also as the nerve centre of this investigation.

In this section, three different means of viewing the virtual double as an indicator of uncertainty are evoked: reflection (Rigid Waves and Eux), the doppelgänger (Eux) and sensory disembodịment (Eux and Sensorama).

\subsection{Trouble and reflection}

One year after Liquid Views, Monika Eleischmanna and Wolfgang Strauss put forward Rigid Waves. The faschnation provoked by identifying oneself with a reflected image gave way o sense of disquiet generated by a deformed self-image. The participant had to face a mirror-screen. A video camera was concealed in the frame in order to film the participant and to allow the projection of his or her image onto the sereen. Therefore, the image would lose its realism as the subject approached the screen.

The technological system takes into account the participant's movements and changes the images accordingly: for example, they can be slowed down, speeded up or frozen. The comparability between what is happening and its reflection is broken. For the artists, this dissimilarity invites the subject to ' $[\ldots]$ see oneself from the outside, to stand side by side with oneself and to discover

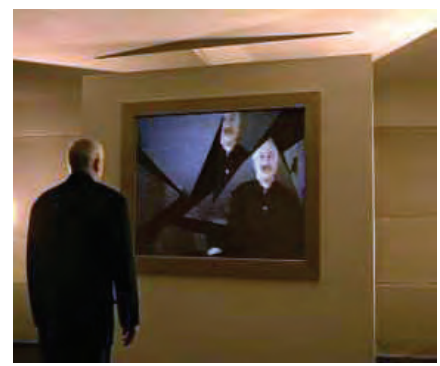

Figure 3: Rigid Waves by Monika Fleischmann and Wolfgang Strauss ( Monika Fleischmann and Wolfgang Strauss. 
other hidden "selfs"' (Fleishmann and Strauss 2004). While Liquid Views references Narcissus' fascination for a watery image, Rigid Waves concentrates on Narcissus' inability to recognize his own reflection. Here the participant is invited to abandon his or her now treacherous mirror-image, in order to construct his or her own identity. This construction process necessitates the recognition of otherness. In this installation, the reflected image becomes a representation of the other.

Crew's productions can be placed at the overlap between installation, theatre and performance. The company integrates the spectator's body into the immersive system from a dramaturgic point of view; the question of the sensitive body is treated here as much from the viewpoint of a fable as through immersive technologies. In Eux, the spectator takes on the role of a patient suffering from agnosia (the loss of ability to recognize things). The perceptive problems caused by this illness provide the starting point for an exploration of our processes of perception and identity construction. The participant is thrown into a modified perception, using a head-mounted display and headphones. The transition from spectator to protagonist occurs through the endorsement of an item of clothing: the subject slips on a hospital gown. The imposition of this restrictive item contributes in its own way to the modification of his or her haptic senses. In essence, the feeling of immersion comes from the $360^{\circ}$ vision that the head-mounted display allows; the projected image follows all the head's movements. These images combine recorded sequences with live scenes. The story is told in realtime by a performer situated next to the participant. The system is not strictly interactive in that the participant is not able to effect the virtual environment or tse his or her initiative. The subject is touched by the performers but is unable to respond to this contact. The actions of the character that he or she portrays are self-reflexive; he or she observes the world and tries to understand how his or her perception has been changed by the illness. The spectator's feelings are linked to the fable. The participant's movements are not free; he or she is generally sitting down, being moved on a trolley or guided by an assistant. In order for the performance to work properly, it is essential that this dramaturgic role is respected.

The immersive environment created by Crew is close to the principles of virtual reality Philippe Fuchs et al. (2006: 7) define the later as a process that allows the subject to 'remove himself from physical reality in order to virtually change the time, place and or type of interaction'. However, this physicar removal is not integral in these performances: rather than an absolute immersion into a virtual world, whereby the participant identifies completely with his or her avatar, the protagonist in Eux is constantly asked to negotiate between his or her bodily perceptions and his or her cognitive process. The company's researcher and dramaturge, Kurt Vanhoutte, along with Nele Wynants and Philippe Bekaert (2008: 159-62), examines how these performances install such sensory deprivation in the spectator. They transform the performance space into a 'transitional space' in which the boundary between the real and the virtual universe is no longer discernable. A complete immersion is prevented by the body's constant appeals; the absence of a virtual world is confronted to the presence of true haptic perceptions.

This constant confrontation between presence and absence is particularly apparent in the mirror-scene in Eux, when the subject is placed in front of his or her supposed reflection. The animate image of a patient, wearing the same gown, with the same headpiece, is projected in front of his or her eyes. Is it his or her own body? The almost simultaneous actions of the video protagonist

1. 2. 3. 4. 5. 6. 7. 8. 9. 10. 11. 12. 13. 14. 15. 16. 17. 18. 19. 20. 21. 22. 23. 24. 25. 26. 27. 28. 29. 30. 31. 32. 33. 34. 35. 36. 37. 38. 39. 40. 41. 42. 43. 44. 45. 46. 47. 48. 49. 50. 51. 52. 
and the participant add to the confusion: in the video, the subject colours in one by one the squares on a crossword that has been placed on his or her thorax. In a manner as close to complete synchronization as possible, a performer leads the protagonist to make the same action on his or her own body. As the camera is omnidirectional, the subject is able to modify the angle of his or her vision and change the projected image in relation to his or her head movements. The dynamic nature of the projected image also accentuates his or her identification with the image - the latter adapts itself to all the subject's head movements. This can look at the face or any other part of the projected body.

In order to determine whether the visually perceived body is his or her own, the subject is obliged to deeply examine his or her visual and haptic senses, which are slightly contradictory. Here the sensory deprivation invites a unique balance between the generally dominant visual perception and the other senses. Kurt Vanhoutte et al. state that the domination of sight allows the subject to identify the filmed body as his or her own; the subjeef appropriates the body that he or she perceives visually. This research is based on a study by Maravita et al. (in Van Houtte et al. 2008: 161), which stated that in multisensory conflicts, vision dominates proprioception and touch. If we take into consideration Ernst and Banks' model (in Furchset al. 2006: 453), it appears necessary to question visual perception's domination, as haptic perceptions also actively participate in the creation of al coherent representation of the world.

Identification with the projected image is only suggested by the system. In the performance, the participant is not actually duped for a very long time, and realizes that the animate image is not his or her own reflection. Moreover, the video is identical for all of the participants, regardless of their morphology or sex. Nevertheless, the confrontation between visual and haptic perception obliges the subject to step back from the visual stimuli that are largely dominant in the spatial construction of our didentity. Here it is the affected flesh

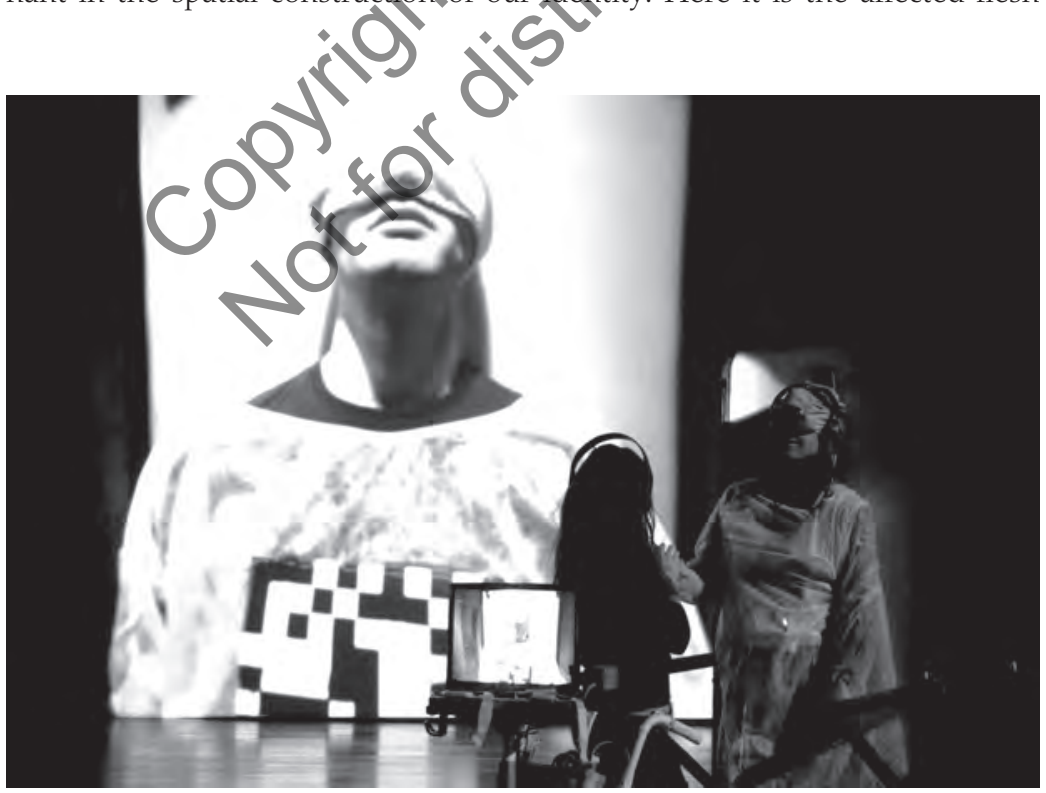

Figure 4: Eux by Crew/Eric Joris $@$ Eric Joris. 
that determines the outline of the physical body and not the supposed visual reflection. This performance forces the subject to take notice of the difficulty of resisting the power of the reflected image and of ignoring visually perceived information. In the manner of Rigid Waves, in reality the self-reflection consists of a representation of otherness. While this 'deception' is obvious in Rigid Waves, it is more concealed in Eux and in order for it to be revealed, it is necessary to have recourse to the body.

\subsection{The doppelgänger}

It is possible to analyse the approach to the double in Eux in three different ways. The second way of doing so comprises the doppelgänger. The Crew company mentions this theme in the programme that accompanies this performance.

The doppelgänger is a very common concept that is frequently encountered in folklore and the paranormal. When discussung this theme, Dixon bases his ideas on the approach of Hans Holzer, borrowed from magic:

The concept of human double (or doubles) has remained a constant factor in folklore and tradition, particulary the belief that every human being accompanied through life by two extensions of his personality, the one good and the other evil; the former luminous and the latter dark and menacing.

(in Dixon 2007: 250)

Dixon applies this point of view to performances, as he believes that the digital double ' $[\ldots]$ is likewise an atternate, and invariably darker embodiment' (2007: 250). All the same, this psychological approach is not characteristic of all artistic explorations of the doppelgänger; for example, Crew neglects it completely. Therefore, we will turn our attention to the issues specific to the digital doppelganger in ternts of self-perception, rather than in terms of the psychological problematics.

In opposing ways, the reflected image and the doppelgänger question the link between identity and otherness. In the first instance, the aesthetic issue consists of creating the feelings of one's own body on the basis of the image of one that is unknown. The aim is that the subject identifies himself or herself as the animate image. On the other hand, Crew's treatment of the doppelgänger seems to have the objective of encouraging a feeling of otherness while at the same time maintaining the perception of one's own image.

At the beginning of the performance, the subject is invited to go into one of the rooms in which an omnidirectional video camera has been placed on a trolley. Although the participant is oblivious to this, the camera films him or her from the moment he or she enters the room. In the final part of the performance, the video of his or her image is projected in front of his or her eyes. When he or she first perceives the visual stimuli of the familiar surroundings the participant may believe that he or she is in the same room, as he or she does not know where he or she has been and is now. A few seconds later, he or she sees an animate image of himself or herself. Once more, the dynamic nature of the multidirectional video intensifies the sense of unease resulting from the combination of recorded image and immediate visual perceptions: the image adapts to all his or her movements. Thus, the subject is immersed in an environment that is also occupied by the virtual double.

1. 2. 3. 4. 5. 6. 7. 8. 9. 10. 11. 12. 13. 14. 15. 16. 17. 18. 19. 20. 21. 22. 
The digital double, moving independent of the participant's movements, prevents the participant from identifying his or her own image. It is no longer a question of a reflection but rather of a veritable virtual alter ego. The presence of the doubles unbalances the individual and the localized character of self. The neuroscientists BignaLenggenhager et al. (2009: 110) have shown that the construction of a unified self can be separate from the origins of its visual perception and the position of its body. Self-representation can be altered by modifying these two parameters; in this way the virtual body intervenes in the perception of the physical body. The integration of a digital double in Eux can be indirectly linked to the experiments led by Lenggenhager et al. In the same way as in Crew's example, this team equipped the subject with a headpiece, which projected the image of his or her own back in front of his or her eyes. Hence, the participant could see his or her own body in front of him or her. At the same time, his or her body was touched with a baton; therefore, he or she perceived a double stimulus, which was both haptic and tisual. This research established that the participants identified themselves with the virtual body, and hence mistook the location of their body, thinking that it was several metres further forward, in the same place as the double. The following diagram illustrates this discovery:

The first square [1] represents the real position of his or her own body; the second square [2] refers to the position that the subject smagines his or her body is in, having been influenced by his or her identifidation with the image of himself or herself that is projected in front of his or her eyes. In such a case, visual perception would play a greater role in the construction of his or her own identity; the subject will rely on his or her haptic senses to a lesser degree.

Both the scientific and the artistic experiences evoked here recognize the dominance of visual stimuli in localizing the situation of one's own body. The doppelgänger's confrontation in Eux is not based on a conflict between

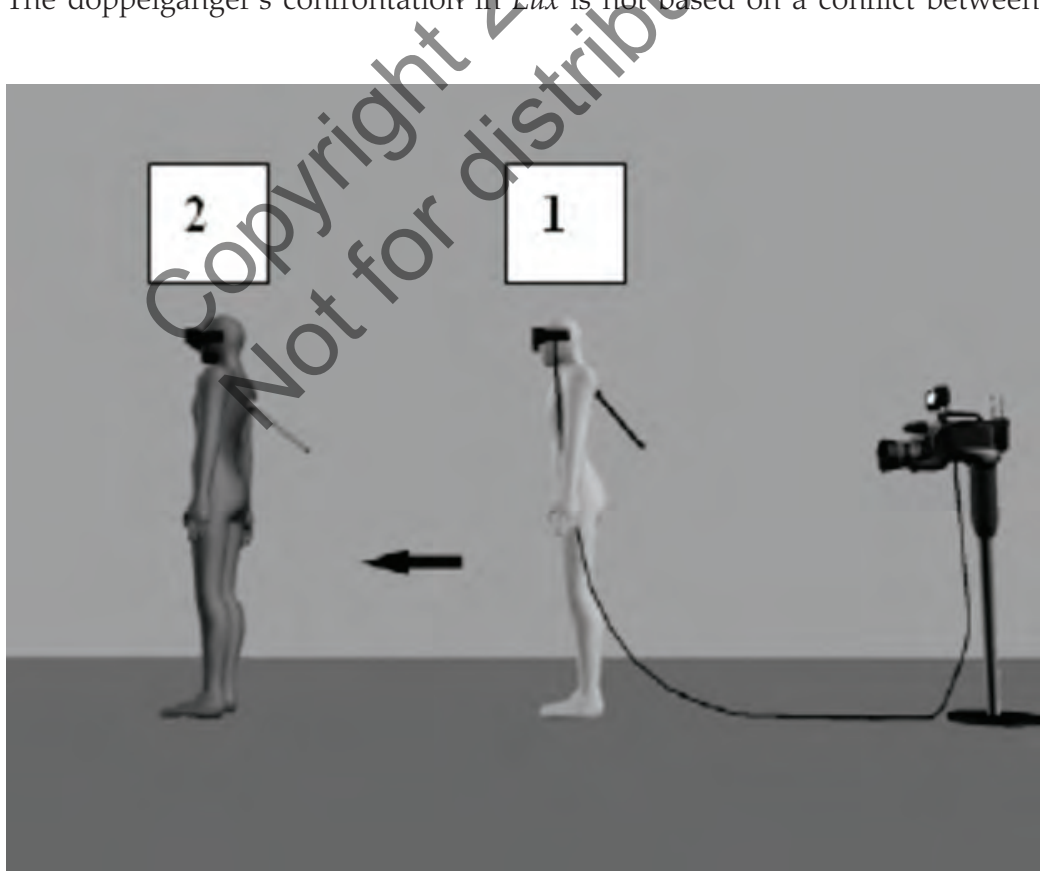

Figure 5: Experiment by Lenggenhager et al. (2008) [doppelgänger]. 
visual and haptic perception. Conversely, in the performance the participant is encouraged to feel uncertain as to the situation of his or her own body. Is he or she in the bedroom as the animated image would suggest? Once he or she realizes that the projected image is in fact a recorded video, the participant is forced to abandon his or her visual stimuli in order to construct a representation of himself or herself and the world that surrounds him or her. In effect, his or her visual stimuli stand testament to the fact that the animated image has become that of another, that of his or her virtual doppelgänger.

The overlapping of identity and otherness through the intermediary of a technological system leads us back to the phenomenon of 'disjonction sans méconnaissance'/'disjunction without misinterpretation' as shown by Pascal Le Maléfan (2005: 529).

He defines this in the following manner:

[...] The recognition of one's own body from a distance, and the fact of being separated from it whilst at the same time continuing to recognise it as one's own, but with the clear feeling that it is no longer the home of one's consciousness. [...] This body has no consideration for the subjectivity which exists externally: he has nothing to do with it and has no perceptible intentions.

(Le Maléfan 2005: 529-30)

Let us straight away try to avoid any misunderstandings: disjunction without misinterpretation does not really occur in Eux, as the double is created by technology and not by the subject's initiative. In the same way as the processes that recreated the effects of agnosia, the company uses omnidirectional video to make the participant perceive things in a troubling manner. In the case of disjunction without misinterpretation, the sight of a faraway body does not endanger the construction of self: the subject is led to determine his or her own body's limits, its position and the home of his or her consciousness. After a few seconds, the particant in Eux distinguishes himself or herself from his or her doppelganger a body that is both his or her own and yet also detached from him or her. He orshe perceives the sense of otherness, while at the same time basing this on his or her own image.

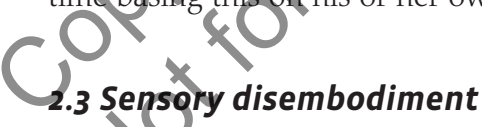

The third and final approach to the double is linked to the aesthetic of uncertainty that exists in the simulation of sensory disembodiment. In the same way as in the disjunction without misinterpretation method, the technological system takes over, in order to compensate for the participant's lack of real perceptive failures. Therefore, a true sensory disembodiment is not produced. Ever since research into this area first started at the end of the nineteenth century, it has been provoking lively and enthusiastic opposition. A first difficulty can be identified as the diversity of terms used. Like many others, Pascal Le Maléfan (2005: 514) laments this diverse terminology and notes that the concept of out-of-body experiences can indicate a great variety of phenomena, thereby engendering a lack of precision. We chose to follow Bernard Andrieu acceptation of 'sensory disembodiment' (2010: 334-53), which brings to light the fact that this phenomenon is essentially concerned with the body and does not concern the more traditional separation of the spirit and the body in the search for transcendence. The distinction between 'corporal intentionality'

1. 2. 3. 4. 5. 6. 7. 8. 9. 10. 11. 12. 13. 14. 15. 16. 17. 18. 19. 20. 21. 22. 
1. and 'intention of the consciousness' is central to Andrieu's theory. He high-

lights the fact that the former precedes the latter, and thus that the construction of the body's identity passes through different stages that come before any form of consciousness:

Intentionality is the expression of a clear association between mental and bodily activities, as the capacity to produce intentional acts with an interactive and adaptive aim with regards to the environment does not engender a spiritual exclusivity. [...] The body, using its motive intentionality, produces a non-conceptual savoir-faire which shows itself in a bodily habit.

(Andrieu 2010: 355)

Andrieu's work noticeably agrees with the neuroscientific work of Christopher Lopez et al. They state that sensory disembodiment results from a subject's failure to integrate multisensory corporal information (Lopez et:al 2008: 149-61). The subject is no longer able to construct a unified identity for himself or herself; because the stimuli are contradictory, he or she is no longer able to combine them to create a coherent representation. The phantom arm experience constitutes a well-known example of such a conflict: information coming from the motor system (the presence of an arm) is contradicted by visual information (the absence of the limb). Therefore, two representations of the body exist side by side.

The simulation of sensory disembodiment that is explored in Eux and Sensorama can be approached from this theoretical angle, as two representations of the body remain in competition?

In these two performances, the phenomenon of disembodiment is not limited to one part of the body but rather concerns the body as a whole.
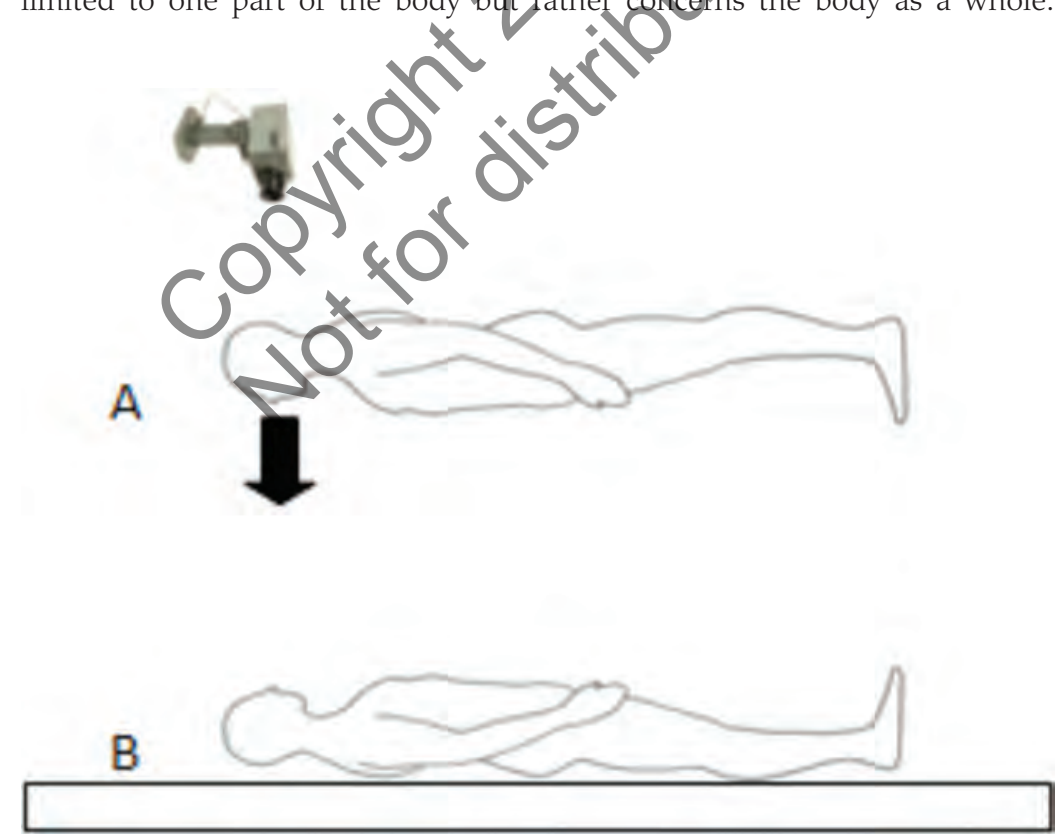

Figure 6: The real position of the body $(B)$ and the overhanging perspective thanks to the headpiece $(A)$ [disembodiment]. 
In each of the sequences, the participant lies down on his or her back. A video camera is placed above him or her. In this way, the subject observes his or her own body from an elevated view point. In Eux, this sequence takes place while the assistants equip him or her with technological material. In Sensorama, disembodiment is more deeply explored, and coupled with an exploration of the haptic senses. An individual lying next to the subject appears on the image. Adopting the same position as the participant, this individual then takes off his or her headpiece and moves closer to the subject, then touching his or her arm for several seconds. In the same way as Telematic Dreaming, virtual contact is created between the flesh and blood participant and a digital character. However, two major differences differentiate the systems. First, in Paul Sermon's installation, the meeting is interactive, while in Sensorama the individual's action is recorded beforehand. Second, in Sensorama, the participant observes the meeting from a modified (elevated) perspective; he or she observes not only the virtual character but also his or herdown actions.

In Eux and Sensorama, the modification of a lying down individual's normal perspective (B) creates the effect of overhanging with regard to what is actually happening: instead of looking towards the celling the subject looks at the floor and hence overhangs his or her own bodf (A). This perspectival modification creates the impression of leaving one body. While the subject locates his or her consciousness in his or her amn body in the case of disjunction without misinterpretation (see Section 22), he or she feels that this has been moved upwards. The participant identifies himself or herself with the overhanging position; his or her consciousness seems to be located in the virtual double. The embodiment, which Lopez et al. (2008: 150) define as the feeling that one's self is located within the physical limits of the body, is disturbed. Henceforth, the self is located outside the body.

Lopez et al. (2008: 154) confirm the importance of the horizontal position in order for a sertsory disembodiment to take place. According to different research, around 80 per cent of such phenomena take place in this position. This can be explained by the reduction of kinaesthetic feelings in this position. At the base of disembodiment, there lies a sensory conflict: the kinaesthetic feelings confirm that the subject is lying down on his or her back yhile the risual perceptions indicate an overhanging perspective. As the kinaestheticleelings are less powerful in an immobile body, the visual information overrides them and creates an out-of-body sensation. The impossibility of combining these two pieces of information into one selfrepresentation (via the cortex) creates a wavering feeling. The self is situated both inside and outside the physical body. In the case of sensory disembodiment, the participant's body is a vessel of both identity and otherness. This overlap operates at the same level as perception and does not constitute the product of cognitive effort.

\section{THE VIRTUAL DOUBLE, BETWEEN IDENTITY AND OTHERNESS}

Digital technology allows us an infinite number of ways of exploring the relationships that exist between identity and otherness, and thus reinforces the intensity of these questions at the heart of performing arts. The integration of the virtual double constitutes a privileged think tank for us to examine the way in which a subject creates his or her identity when he or she is confronted with his or her own image. The latter can be the source of a feeling of either identity or otherness. The confrontation between the participant and his or her double

1. 2. 3. 4. 5. 6. 7. 8. 9. 10. 11. 12. 13. 14. 15. 16. 17. 18. 19. 20. 21. 22. 23. 24. 25. 26. 27. 28. 29. 30. 31. 32. 33. 34. 35. 36. 37. 38. 39. 40. 41. 42. 43. 44. 45. 46. 47. 48. 49. 50. 51. 52. 
1.

has been studied from two different aesthetic angles. The first, brought about by an enthusiasm for new technology, concerns the fascination one feels for one's own digital image. The second rather concerns the uncertainty that is felt with regard to the nature of this supposed self-representation.

Steve Dixon rejects the idea that digital artists are concerned with the search for a sort of transcendence, whereby the spirit would detach itself from the physical body in order to identify itself fully with its virtual double. While both types of creation take into account the participant's body, it is only in the second set of examples that the question of a reactive body is given an important role in the artistic research. Meetings with one's reflection or doppelgänger, along with the sensation of disembodiment, constitute three intensely sensorial experiences. In all of them, the participant is encouraged to give less importance to his or her cognitive senses in order to allow his or her sensations to create a representation of himself or herself and the world that surrounds him or her. The overlap between identity and otherness is therefore to be found at the very heart of the sensitive body.

\section{REFERENCES}

Andrieu, Bernard (2010), ‘L’Externalisation du soi para décorporation sensorielle/The outsourcing of the self by the sensory out-of-body experience', L'Evolution psychiatrique, 75: 2, pp. 334-533.

Birringer, Johannes (1999), 'Contemporary performance/technology', Theatre Journal, 51: 4, pp. 361-81.

Causey, Matthew (2009), Theatre and Performance in Digitat Culture, London: Routledge.

Dixon, Steve (2007), Digital Performance, Cambridge:MT Press.

Fleischmann, Monika and Strauss, Wolfgang (2008), 'Staging of the thinking space. From immersion to kerformative presence', in Uwe Seifert et al. (eds), Paradoxes of Interäticity, Bielefeld: Transcript Verlag, 266-81.

- (2010), 'Images of the body in the house of illusion', http://netzspannung .org. Accessed October 2041.

Fuchs, Philippe and Moreau, Guillaume (2006), 'Introduction à la réalité virtuelle/Introduction to Virtual Reality', in Philippe Fuchs et al. (eds), Le Traité de la réalitếvirtuelle. Volume 2: L'interfaçage, l'immersion et l'interaction en environnement vituluel/The Treatise of Virtual Reality. Volume 2: Interfacing, immersion and interaction in virtual environment, Paris : ENSMP Presses, pp. 3-30.

Heim, Michael (1995), 'The design of virtual reality', in Mike Featherstone et al. (eds), Cyberspace, Cyberbodies, Cyberpunk, London: Sage, pp. 65-77.

Lécuyer, Anatole (2006), 'Le Retour pseudo-haptique/The pseudo-haptic feedback', in Philippe Fuchs et al. (eds), Le Traité de la réalité virtuelle. Volume 2: L'interfaçage, l'immersion et l'interaction en environnement virtuel/ The Treatise of Virtual Reality. Volume 2: Interfacing, immersion and interaction in virtual environment, Paris: ENSMP Presses, pp. 451-70.

Le Maléfan, Pascal (2005), 'La sortie "hors du corps" est-elle pensable par nos modèles cliniques et psychopathologiques? Essai de clinique d'une marge. A propos d'un cas/Is the out-of-body experience conceivable by our clinical and psychopathological models? The clinical experiment of a margin. About a case', L'Evolution psychiatrique, 70: 3, pp. 513-34.

Lenggenhager, Bigna, Mouthon, Michael and Blanke, Olaf (2009), 'Spatial aspects of bodily self-consciousness', Consciousness and Cognition, 18, pp. 110-17. 
Lopez, Christopher, Halje, Pär and Blanke, Olaf (2008), 'Body ownership and embodiment: Vestibular and multisensory mechanisms', Neurophysiologie Clinique/ Clinical Neurophysiology, 38: 3, pp. 149-61.

Lupton, Deborah (1995), 'The embodied computer/user', in Mike Featherstone et al. (eds), Cyberspace, Cyberbodies, Cyberpunk, London: Sage, pp. 97-112.

Robins, Kevin (1995), 'Cyberspace and the world we live in', in Mike Featherstone et al. (eds), Cyberspace, Cyberbodies, Cyberpunk, London: Sage, pp. 136-55.

Vanhoutte, Kurt Wynants, Nele and Bekaert, Philippe (2008), 'Being inside the image. Heightening the sense of presence in a video captured environment through artistic means: the case of CREW', in Anna Spagnolli et al. (eds), Presence 2008: Proceedings of the 11th International Workshop on Presence in Padova, Padova: LibrariaUniversitariaPadova, pp. 159-62.

\section{SUGESSTED CITATION}

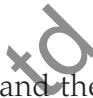

Bouko, C. and Slater, N. (2011), 'Identity, otherness and the virtual double', Technoetic Arts: A Journal of Speculative Research 9: 1, pp. 17-30, doi: 10.1386/ tear.9.1.17_1

\section{CONTRIBUTOR DETAILS}

Catherine Bouko (Ph.D.) is an associate professor in the department of performing arts at the Université Libre de Bruxelles. Her works primarily concern the reception of postdramatic and digital performances. In 2010, she published Théâtre et Réception. Le Spectatêtr postdramatique by the Peter Lang Editions.

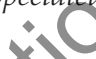

Natasha Slater has transtated the article from French.

16.

17.

18.

Contact: Université Libre de Brtuxelles, Av. F. Roosevelt 50 CP 123, 1050 Brussels,

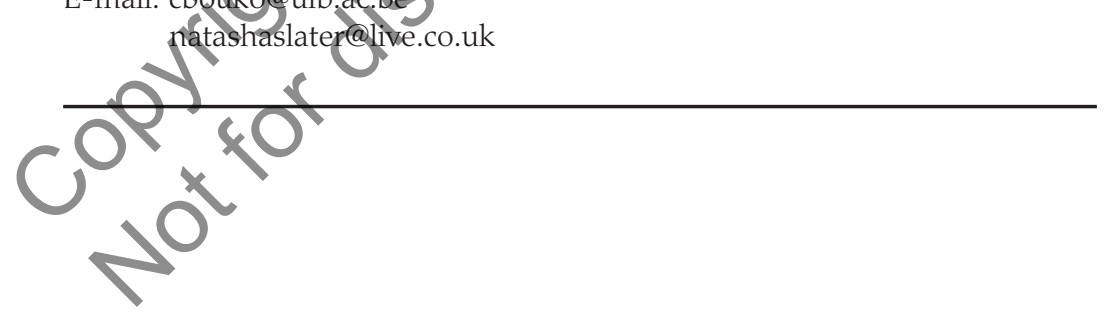

